Review article

\title{
Instrumental swallowing assessment in children
}

Rubasinghe $\mathrm{MS}^{1}$, Jayathilake SMSW ${ }^{2}$, Udugama KLLG ${ }^{3}$

${ }^{1-}$ Consultant ENT Surgeon, Lady Ridgeway Hospital, Colombo, Sri Lanka.

2. Speech and Language Therapist, Lady Ridgway Hospital for Children, Colombo.

3-. Speech and Language Therapist, Sirimavo Bandaranaike Specialized Children's Hospital, Peradeniya.

\begin{abstract}
Children can present with a wide range of swallowing impairments. This may affect from neonates, infants, toddlers, young children to early teens. The most serious outcome of a severe swallowing impairment is gross aspiration leading to violation of airway and its consequences such as recurrent aspiration pneumonias, sepsis, poor weight gain, failure to thrive and long term developmental sequel.

Assessment of swallowing is done in children using perceptual clinical swallowing assessment by a speech and language therapist. This is a subjective assessment and may not clearly identify the defective phase of swallowing and may miss silent aspiration.

Instrumental swallowing assessment is a method to identify swallowing impairment by objective evaluation of the entire swallowing process. This would identify the phase and quantify the severity of the impairment. It is mainly done in two ways. i.e. the Functional Endoscopic Evaluation of swallowing (FEES) and Video Fluoroscopic Swallow Study (VFSS).
\end{abstract}

Both are valuable methods as they separately assess different phases of swallowing. The results are invaluable in further treatment of these children to overcome or mitigate their impairment. FEES involves inserting a fibro-optic pediatric laryngoscope in the child's pharynx via the nose and simultaneous observation of swallowing mechanism while feeding orally. VFSS involves fluoroscopic viewing of the swallowing process while giving food mixed with a radio opaque substance. VFSS is further helpful in intra procedural positional maneuvers and change in food consistencies to overcome the given impairment.

Instrumental swallowing assessment is a valuable tool in assessing and subsequent managing swallowing impairment in children. They are reliable objective tests in the management in paediatric dysphagia.

Key words: Paediatirc, dysphagia, Flexible fibro- optic swallowing study (FEES), Video fluoroscopic Swallow study (VFSS), laryngeal Penetration, Aspiration.

Copyright: () 2022 Rubasinghe MS.

This is an open access article distributed under the Creative Commons Attribution License (CC BY 4.0) (c) (7) This license lets others distribute, remix, tweak, and build upon the work, even commercially, as long as they credit the original author for the creation.

Funding: None

Competing interest: None

Correspondence: Dr. M.S. Rubasinghe (mihirirubaent@gmail.com) 
Accepted Date: $16^{\text {th }}$ Jan 2022

Published Date: $26^{\text {th }}$ Feb 2022

\section{Introduction}

Paediatric swallowing disorders are common and the incidence is increasing. They occur approximately in $1 \%$ of children in the general population ${ }^{1}$. Paediatric dysphagia occurs commonly with multiple and complex medical and developmental disorders ${ }^{2,3}$. In this population the incidence is estimated to be from 33 to $80 \%{ }^{4,5}$.A large number of these children are born prematurely. Approximately $37-40 \%$ of children assessed for feeding and swallowing disorders are born prematurely at less than 37 weeks of gestation ${ }^{6,7}$. Increased survival rates of children with histories of prematurity, low birth weights and complex medical conditions might explain the recent increase in paediatric dysphagia ${ }^{8}$.

Swallowing pathologies can have negative effects on pulmonary health as airway violation may occur. Consequences of this may lead overall poor nutrition hence growth and development.

Swallowing is a dynamic process. Components of anatomy related to swallowing of an infants are different from an adult. In a child the oral cavity is smaller, and edentulous. The larynx and hyoid bone are higher in the neck to the oral cavity. The epiglottis touches the soft palate and therefore the larynx is opened to the nasopharynx ${ }^{9}$.

Swallowing requires both voluntary and involuntary coordination and classically is divided in to 3 phases. They are oral, pharyngeal and oesophageal phases. The oral phase constitutes both preparatory and transit phases. Triggering of the swallowing reflex occurs next. During the pharyngeal phase the bolus is transported to the pharynx, and then the oesophageal phase consists of the bolus being transported through the cervical and to the distal oesophagus.

Evaluating the severity of dysphagia is more challenging in children than in adults especially when involving multiple aetiologies ${ }^{10}$.

Table1: Common presentations in dysphagia in Children

\begin{tabular}{|l|l|}
\hline Phase & Presentation \\
\hline Oral Phase & $\begin{array}{l}\text { Absent oral reflex, primitive/neurological oral reflex, weak suck, } \\
\text { uncoordinated suck, immature biting/ chewing, disordered biting /chewing, } \\
\text { poor bolus propulsion, poor bolus containment. } \\
\text { Absent swallow reflex, delayed triggering of the swallow, suck, swallow } \\
\text { breath incoordination }\end{array}$ \\
\hline Pharyngeal phase & $\begin{array}{l}\text { Laryngeal penetration, aspiration, choking, pharyngeal residue, } \\
\text { nasopharyngeal reflux }\end{array}$ \\
\hline Oesophageal phase & $\begin{array}{l}\text { Delayed transit time, gastro oesophageal reflux-, stagnation of food due to } \\
\text { obstruction at different levels and subsequent regurgitation and aspiration of } \\
\text { the content }\end{array}$ \\
\hline
\end{tabular}


A child with a disordered swallowing mechanisms may show delayed progression of normal feeding skills, recurrent respiratory distress and consequently growth deficiency. Aspiration is one of the abnormalities that may be encountered and consist of passage of ingested material, refluxed contents, or oral secretions through the vocal folds into the lower respiratory tract. Recurrent or chronic aspiration is a serious risk factor in the paediatric population resulting in infection, chronic lung disease and even death 1 .

Aspiration may show typical symptoms of coughing, chocking and difficulty in feeding. In some children none of these symptoms are present except for recurrent chest infections. This may be due to a phenomenon called silent aspiration.

Table 2: Aetiologies of paediatric dysphagia ${ }^{1}$

\begin{tabular}{|c|c|c|}
\hline Stage of dysphagia & Aetiology & Example \\
\hline \multirow[t]{3}{*}{ Oro pharyngeal dysphagia } & Neurological disorders & $\begin{array}{l}\text { Myopathy , birth asphyxia, } \\
\text { cerebral palsy , microcephaly, } \\
\text { periventricular leucomalacia, } \\
\text { Motor neuron disease }\end{array}$ \\
\hline & Infective pathologies & $\begin{array}{l}\text { Neuro syphilis, herpetic } \\
\text { meningo-encephalitis, } \\
\text { congenital cytomegalo virus } \\
\text { infection, dermatomyositis, }\end{array}$ \\
\hline & Structural disorders & $\begin{array}{lcc}\text { Restricted lingual } & \text { frenulum, } \\
\text { cleft } & \text { palate/lip, atresia/stenosis } \\
\text { e.g., } & \text { CHARGE } & \text { syndrome, } \\
\text { goiter, caustic } & \text { injuries, } \\
\text { congenital laryngomalacia }\end{array}$ \\
\hline \multirow[t]{3}{*}{ Oesophagial dysphagia- } & Motility disorders & $\begin{array}{l}\text { Achalasia, scleroderma, diffuse } \\
\text { oesophageal spasm }\end{array}$ \\
\hline & Extrinsic compression & $\begin{array}{l}\text { Vertebral anomalies , foreign } \\
\text { bodies ,mediastinal lesions }\end{array}$ \\
\hline & Oesophagitis & $\begin{array}{l}\text { Herpes simplex virus, candida, } \\
\text { Gastro oesophagial reflux } \\
\text { disease. } \\
\text { Eosinophilic Oesophagitis }\end{array}$ \\
\hline
\end{tabular}

\section{Assessment of dysphagia}

The assessment of swallowing disorders is primarily done by a speech and language therapist (SLT) with experience in feeding disorders. Detailed history is taken including prenatal, birth history, and immediate post- natal events, neonatal and childhood events. Perceptual assessment with suitable types of food is done following this. Perceptual assessment is mostly subjective as the swallowing mechanism is assessed by using indirect methods. Subjective assessment fails to identify the level of impairment accurately and does not confirm or exclude silent aspiration. 


\section{Objective Swallowing assessment methods}

A reliable method is required for objective assessment of swallowing in these children. There are two instrumental swallowing assessment tools available as shown below:

Functional endoscopic evaluation of swallowing (FEES)

Video fluoroscopic evaluation of swallowing (VFSS) or Modified Barium swallow (MBS)

Both methods are complementary to each other. FEES involves using a flexible naso-pharyngo laryngoscope in the child while the child swallows. FEES is a sensory testing for laryngeal adductor response (LAR) and can be added to Fibro optic Endoscopic evaluation of Swallowing and sensory test (FEEST).

FEES views the pharynx and larynx directly while the child swallows the given consistencies. This tool mainly assesses pharyngeal phase of swallowing. It observes dynamic changes of the larynx and pharynx during the pharyngeal phase of swallowing and passage of a bolus. It can be performed at the bedside and repeated in a brief period and in different clinical conditions and considered as a very valuable instrumental method in follow up.

During the FEES study direct visualization of the pharynx is done using a flexible video laryngoscope while the child swallows various food items. These food items can be coloured with permitted food colouring for better visualization. FEES provides images of larynx and hypopharynx before and after, but not during swallowing. Visualization of the pharyngeal phase of swallowing allows the detection of structural abnormalities and swallowing impairments as well as an assessment of aspiration risks. Direct assessment of oral and oesophageal phases is not possible and the inferences could be made as indirect observations of these 2 phases.

Using a flexible scope in a child while the child actually swallows at the same time may be very uncomfortable. Children seems to be agitated by the presence of a foreign body in their upper aero digestive tract and may refuse to swallow. Anatomical restrictions such as nasal vestibular stenosis or gross nasal septal deviation is a contra indication for FEES assessment.

Contrast to FEES, VFSS allows the assessment of swallowing in all the stages. It allows dynamic view of swallowing during oral, pharyngeal and cervical phases.

During the assessment the child is presented with a contrast material impregnated food in various consistencies preferably in an upright posture (seated). The type of food and the tested consistencies are chosen to suit the child's swallowing skills and age. Video fluoroscopic real time imaging is used to view the swallowing process. Literature supports that the frame rate of at least 25-30 per second is required to detect subtle penetration/aspiration ${ }^{11,12,13}$. Depending on the findings, during VFSS the clinician is given the opportunity to try multiple food textures and different postural corrective maneuvers to overcome the detected pathology. Change of delivery system, change of bolus speed, and bolus viscosity can be altered to suit the identified pathology. This can be done at the end of the VFSS study while still under the fluoroscopic guidance. 
Penetration/Aspiration score (PAS score) is widely employed interval scale for a reliable quantification of penetration and aspiration events observed during VFSS. Penetration is scored from 2 to 5 and aspiration is indicated from score of 6 to 8. Another abnormality seen on VFSS is epiglottic undercoating which occurs when material penetrates underneath the epiglottis above the laryngeal vestibule ${ }^{15}$. Multiple swallows have to be assessed during VFSS to detect latent or subtle swallowing impairments.

Table 3: Penetration/Aspiration Scale byRosenbek et al $1996^{14}$

\begin{tabular}{|l|l|}
\hline Scale & \multicolumn{1}{|c|}{ Description } \\
\hline 1 & No penetration or aspiration \\
\hline 2 & Penetration, contrast remain above the vocal folds, subsequently ejected \\
\hline 3 & Penetration, contrast remain above the vocal folds ,not ejected \\
\hline 4 & Penetration, contrast contract vocal folds subsequently ejected \\
\hline 5 & Penetration, contrast contact vocal folds not ejected \\
\hline 6 & Aspiration (contrast below vocal folds) subsequently ejected (at least in to larynx) \\
\hline 7 & Aspiration (contrast below vocal folds) not ejected despite effort \\
\hline 8 & Aspiration (contrast below vocal folds) no effort made to eject \\
\hline
\end{tabular}

Primary limitation to VFSS is exposure to radiation. Other limitations such as the change of taste of food once the radio opaque material is added, may make familiar food unpalatable to these children. Further dark radiology rooms with bright light shining next to the child's face may intimidate them.

Although the gold standard tool to assess dysphagia in children has not been agreed upon, both VFSS and FEES can be complementary, and both provides accurate diagnosis of dysphagia in paediatric populations when applied and interpreted by experienced clinicians. Both methods have comparable sensitivity, specificity, and predictive abilities ${ }^{16,17}$. In addition, FEES requires a paediatric flexible scope which is operated by an ENT surgeon in the presence of a SLT.

\section{Sri Lankan perspective}

Instrumental swallowing assessment for children was initiated in Sri Lanka in 2019 at Lady Ridgeway Hospital for Children, Colombo by the first author. This is corroborated with the hospital speech and language therapy department and the ENT department. FEES assessments were started in October 2018 and are done in the ENT department. During the study the child is seated or supported in the special chair in the ENT workstation. The height of the chair is adjustable vertically and the backrest can be adjusted to suit the correct positioning of the child. The child either sits alone or is placed on the first caregivers lap while the ENT surgeon passes the $2.9 \mathrm{~mm}$ diameter video flexible naso- pharyngoscope (Karl Stortz Germany) via the nose. Once the tip of the scope is just above the pharyngeal level, the second caregiver starts to feed the child. The liquids are coloured with permittable blue food colouring and the semisolids /solid food is coloured with green food colouring. Liquids are given using a feeding spoon or a feeding bottle. The semi solid /solid food is given using a feeding spoon or is held by the child or the care giver. The Speech and language therapist is present during the procedure to instruct on the type and amount of food and the volume given in each feed. Short video clips are recorded for each food 
consistencies. If clear penetration or aspiration is noted or child develops cough /respiratory distress, further the assessment is abandoned.

Video Fluoroscopic swallow assessment (VFSS) was started in October 2019. This is done in the hospital Radiology department in the presence of the ENT Surgeon, Speech and language therapist and the radiographer operating the Fluoroscopy unit. The child is kept either on the caregiver's lap or on a special chair designed to keep the child sit straight. The food items prepared by the family are used and modified according to the required consistency by adding radio opaque Ioxehol solution (Omnipaque by GE Healthcare, Ireland). The first caregiver feeds the child from the front and the second caregiver keeps the child on the lap or support the head from behind. The speech and language therapist gives directions to the amount and the timing of prepared food items. The fluoroscopic image is viewed by the ENT surgeon and Speech therapist to detect the presence of swallowing impairment, quantify it and identify the level. If there is any respiratory distress or evidence of aspiration the test would be terminated.Resuscitation facilities were readily available for both assessments, if needed.

In an ongoing unpublished series of 24 patients who underwent VFSS from August 2019 to December 2020 in Lady Ridgeway Hospital for children, demographic factors, source of referral, underlying medical conditions and concerns for referrals were assessed. The mean age of the population was 39 months. Out of this series $54 \%$ studies children were less than 24 months.

Patient were predominantly referred by the SLT department and to a lesser number by ENT, Neurology, Pulmonology, general medical and Rheumatology departments. The main concern for referral was features of aspiration related events. Underlying medical conditions of this population showed that the children with central nervous system disorders topped, out of which seizure disorders were the commonest.

Penetration /aspiration was observed and assessed using the universal PAS score ${ }^{14}$. Penetration alone was noted in $16 \%$ and aspiration was noted in $58 \%$ of the population. Level of impairment was worse in pharyngeal phase in $91 \%$. In the final outcome out of $25 \%$ of studies population there was objective evidence to adopt a long term alternative feeding method and subsequently referred for s per cutaneous gastrostomy (PEG) insertion. At the end of the study 54\% of children had some sort of a change in their hitherto feeding practice.

Children less than 24 months had the highest yield in identifying aspiration in this series (87\%). This was very significant as identifying the degree and level of impairment in this young age group facilitated the health care team to correct them before any short term and long term sequel such as recurrent aspiration pneumonia, poor weight gain, overall developmental regression occurred.

Parents who have been refusing long term alternative feeding methods such as PEG insertions could be convinced for the procedure with the objective evidence of clear/ silent aspiration.

The most significant limiting factor in VFSS in this series was the frame rate in the available Fluoroscopy machine which was 20 frames/second whereas the recommended rate is $25-30^{11,12}$. This could not be corrected as the machine has a build in rate which was fixed. (Shimadzu Flexovision F3 from Shimadzu Corporation Japan). The other limiting factor we observed was excessive crying of children during the 
assessment (45\%). The fluoroscopy room being dark and the bright beam of the light shining adjacent to the side of the face was found to be the reason. Nevertheless, familiar care givers, familiar food and utensils were practiced mitigating the factors.

\section{Conclusion}

Children and infants can present with swallowing difficulties. These difficulties may cause short term problems can interfere their rapidly changing body systems and can interrupt normal development. This may cause serious injury to their pulmonary health and general development.

Children who are mostly vulnerable are the ones with cerebral palsy, acquired and traumatic brain injury, other neuro muscular disorders, cranio- facial malformations, airway malformations, post cardiac surgery, children born before 34 weeks and children with gastrointestinal disease. Intervention has to be targeted at the cause of the problem in order to be effective. For this reason, a thorough assessment is necessary. VFSS and FEES are the mostly used instrumental swallowing assessments in children. Once the nature and any possible factors contributing to the swallowing difficulties are identified, a treatment plan can be developed. Close coordination among ENT, SLT, medical and radiology department is paramount for a successful clinical outcome in these children.

\section{References}

1. Lo Re G ,Vernuccio F, Di Vittorio M L, Scopellity L, Di Piazza A, . Terranova M C et al : Swallowing evaluation with videofluoroscopy in the paediatric population. ActaOtorhinolaryngologicaItalica 2019;39:279-288 , https://doi.org/10.14639/0392-100X-1942. PMid:30933173 PMCid:PMC6843585

2. Jones PM , Feeding disorders in children with multiple handicaps. Dev Med Child Neurol1989;31:404-6.

3. Loughlin GM. Respiratory consequences of dysfunctional swallowing an aspiration. Dysphagia 1989;3:126-30.https://doi.org/10.1007/BF02407130.PMid:2700953

4. LinscheidTR . Behavioral treatments for pediatric feeding disorders. BehavModif 2006;30:623.https://doi.org/10.1177/0145445505282165.PMid:16332643

5. Field D, Garland M ,Wiliams K. Correlates of specific childhood feeding problems . J Paedaitr Child Health 2003;39:299-304. https://doi.org/10.1046/j.1440-1754.2003.00151.x. PMid:12755939

6. Newman LA ,Keckley C, Petersen MC, Hamner A. Swallowing function and medical diagnoses in infants suspected of dysphagia. Pediatric 2001;108:E106. https://doi.org/10.1542/peds.108.6.e106.PMid:11731633

7. Rommel N , De Meyer AM, Feenstra L ,Veereman-Wauters G ,The complexity of feeding problems in 700 infants and young children presenting to a tertiary care institution .J PediatrGastroenterol Nutr2003;37:75-84. https://doi.org/10.1097/00005176-20030700000014PMid:12827010

8. Martin JA, Hamilton BE, Sutton PD, Ventura SJ, Menacker F, Kirmeyer S, et al . Births :Final data for 2005.Natl Vital Stat Rep 2007;56:1-103.

9. Matsuo K, Palmer J B, Anatomy and physiology of feeding and swallowing- normal and abnormal. Phys Med Rehabil Clin N Am 2008;19:691707.https://doi.org/10.1016/j.pmr.2008.06.001 PMid:18940636 PMCid:PMC2597750 
10. Soon Ook Bae, Gang Pyo Lee, Han Gil Seo, Byung-Mo Oh, Tai Ryoon Han: Clinical Characteristics Associated with Aspiration or Penetration in Children with Swallowing Problems. Annals of Rehabilitation Medicine 2014; 38(6): 734-731. https://doi.org/10.5535/arm.2014.38.6.734. PMid:25566471 PMCid:PMC4280368

11. Bomilha HS, Blair J, Carnes B, et al. Preliminary investigation of the effect of pulse rate on judgement of swallowing impairment and treatment recommendations. Dysphagia.2013;28:528538.https://doi.org/10.1007/s00455-013-9463-z.PMid:23559454 PMCid:PMC3762944

12. Cohen MD, Can we use pulsed fluoroscopy to decrease the radiation dose during video fluoroscopic feeding studies in children? Clin Radiol.2009;64:70-73. https://doi.org/10.1016/j.crad.2008.07.011PMid:19070700

13. Henderson M, Miles A, Holgate V, et al. Application and verification of quantitative objective video fluoroscopic swallowing measures in a pediatric population with dysphagia.J Pediatr.2016;178:200-05.e1.https://doi.org/10.1016/j.jpeds.2016.07.050. PMid:27568657

14. Rosenbek JC, Robbinson JA, Roecker EB, et al. A penetration aspiration scale. Dysphagia 1996:11;93-98.https://doi.org/10.1007/BF00417897.PMid:8721066

15. Hiorns MP, Ryan MM. Current practice in Paediatric videofluoroscopy .PediatrRadiol 2006;36:911-9.https://doi.org/10.1007/s00247-006-0124-3.PMid:16552584

16. Gomes GF, Rao N, Brady S, et al .Gold standard ? Analysis of the videofluoroscopic and fiberoptic swallow examination .J Applied Res 2003;3;89-96.

17. Wu CH, Hsiao TY, Chen JC, et al Evaluation of swallowing safety with fibro optic endoscope: comparison with videofluoroscopic technique. Laryngoscope1997 ;107:396401.https://doi.org/10.1097/00005537-199703000-00023.PMid:9121321 